TÀI LIỆ THAM KHẢO

1. Lê Quang Sơn, Nguyễn Văn Chừng và Nguyến Văn Sách (2009), "Nghiên cứu đăc điểm gây mê hồi sức trong, phẫu thuật nội soi ruột thửa có bơm thán khí vào ô bung".

2. Nguyễn Mạnh Hông và Công Quyết Thắng (2008). "Nghiên cứu Gây mê Hồi sức trong mổ nôi soi ổ bung, bênh viên Hữu Nghi Hà Nôii".

3. Nguyễn Ngơc Ânh và cộng sự (2006). "Gây mê trong mố nội soi ổ bụng", Bài giảng Gây mê hồi sức tập II. Nhà xuất bản Y học, tr 311-318.
4. Nguyễn Quốc Kính (2013). "Theo dõi trong mổ nội soi" Gây mê hồi sức cho phẫu thuật nội soi. Nhà xuất bản Giáo dục Việt Nam, tr 48-49.

5. Nguyễn Sỹ Linh (2018). Gây mê cho phẫu thuật nội soi và phẫu thuâtt Robot, truy cập ngày 20/11/2018, tai https://www.gaymehoisuc. net/2018/10/gay-me-cho-phau-thuat-noi-soi-vaphau.html

6. Trân Bình Giang và công sự (2018). "Lịch sử của nội soi và phâu thuật nội soi", Phẩu thuật nội soi ổ bụng. Nhà xuất bản Y học, tr 15-47.

\title{
ĐÁNH GIÁ HIÊUU QUẢ CỦA PHÁC Đồ Có BORTEZOMIB TRONG ĐIỀU TRI BƯớC ĐẦU ĐA U TỦY XƯO'NG TẠI BỆNH VIÊ̂N K
}

\section{TÓM TĂT}

Mục tiêu: đánh giá hiệu quả của phác đồ có bortezomib trong điều trị bưởc đâu đa u tủy xương tai bệnh viện $\mathrm{K}$. Đối tượng và phương pháp: Nghiên cứu tiến cứu mô tả tiến hành trên 44 bênh nhân được chẩn đoán xác định đa u tủy xương điều trị hóa chất phác đồ có bortezomib tại Bệnh viên K từ 05/2019 đến 10/2021. Kết quả: Độ tuổi trung bình của bệnh nhân là 59 tuổi, tỉ lệ nam/nữ: 1,1. Đa số bệnh nhân vào viện vì đau xương 91\%. Hầu hết các bệnh nhân có nhiều tổn thương $88,6 \%$. Vị trí tổn thương hay gặp nhất là xương cột sống thắt lưng 75\%. Thể bệnh hay gặp nhất là IgG Kappa 38,6\%, IgG Lambda 18,2\%. Phác đồ VRD và VTD có tỉ lệ kiểm soát bệnh cao $100 \%$ và $96,6 \%$ trong khi phác đồ VCD chỉ đạt $60 \%$. Độc tính hay gặp là độc tính thân kinh ngoại vi ở nhóm điều trị phác đồ VTiD 27,6\%, nhóm điều trị phác đồ VTD hay gặp độc tính ha bạch câu $40 \%$ và độc tính trên da 30\%. Kết luận: Điều trị đa u tủy xương bằng phác đồ 3 thuốc có bortezomib cho tỉ lệ đáp ứng và độ an toàn cao.

Tư khóa: Đa u tủy xương, phác đồ có bortezomib

\section{SUMMARY}

ASSESSMENT THE EFFECTIVENESS OF THE BORTEZOMIB-CONTAINING REGIMENS IN THE FIRST LINE TREATMENT OF MULTIPLE MYELOMA AT K HOSPITAL

Objectives: To evaluate the effectiveness of bortezomib-containing regimens in the first line treatment of multiple myeloma at $\mathrm{K}$ hospital. Subjects and methods: A prospective descriptive study conducted on 44 multiple myeloma patients received bortezomib regimens chemotherapy at $\mathrm{K}$ Hospital from 05/2019 to $10 / 2021$. Results: The

\section{*Bênh viên $K$}

Chịu trách nhiệm chính: Nguyễn Tiến Quang

Email: ntienquangbvk@gmail.com

Ngày nhận bài: 21.10.2021

Ngày phản biên khoa họ: 17.12.2021

Ngày duyệt bài: 27.12.2021 average age of the patients was 59 years old, the male/female ratio: 1.1. The majority of patients admitted to the hospital because of bone pain $91 \%$. Most of the patients had multiple lesions $88.6 \%$. The most common injury site is the lumbar spine, $75 \%$. The most common disease form is IgG Kappa $38.6 \%$, IgG Lambda $18.2 \%$. VRD and VTD regimens have high disease control rates (100\% and $96.6 \%)$ while disease control rates of VCD regimens is $60 \%$. The most common toxicity was peripheral neurotoxicity in the group treated with the VTD regimen $27.6 \%$, the group treated with the VTD regimen often experienced leukopenia $40 \%$ and cutaneous toxicity $30 \%$. Conclusion: Multiple myeloma treatment with bortezomib-containing regimens has a high response rate and safety.

Key words: multiple myeloma, bortezomibcontaining regimens.

\section{I. ĐĂT VẤN ĐỀ}

Đa u tủy xương (Multiple Myeloma - MM) thường được đặc trưng bởi sự tăng sinh của các tế bào plasma tạo ra globulin miễn dịch đơn dòng. Các tế bào plasma tăng sinh trong tủy xương có thể dẫn đến phá hủy xương trên diện rộng với các tổn thương tiêu xương, thiểu xương và gãy xương bệnh lý ${ }^{1}$.

MM là một bệnh ung thư không phổ biến, chiếm khoảng 1 đến 2 phần trăm tổng số các bệnh ung thư và hơn 17 phần trăm các bệnh ác tính huyết học. MM phổ biến hơn ở nam giới hơn phụ nữ (tỉ lệ nam: nữ 1,4:1) và thường gặp hơn ở những người Mỹ gốc Phi; tî lệ mắc thấp ở người châu Á. Trên toàn thế giới, có khoảng 160.000 trường hợp mắc và 106.000 trường hợp tử vong mỗi năm do $\mathrm{MM}$. Tuổi trung bình khi chẩn đoán là 65 đến 74 tuổi; chỉ 10 phần trăm bệnh nhân dưới 50 và và 2 phần trăm bệnh nhân dưới 40 tuổi. Nguy cơ mắc MM tăng theo chỉ số khối cơ thể 1,2 . 
Điều trị được chỉ định cho tất cả các bênh nhân được chẩn đoán xác định đa u tủy xương phụ thuộc vào phân tầng nguy cơ, khả năng và điều kiện để ghép tế bào gốc ${ }^{2}$. Hóa trị là liệu pháp điêu trị căn bản cho bệnh nhân đa u tủy xương có ghép tủy hay không. Các hướng dẫn hiện nay khuyến nghị sử dụng các phác đồ có bortezomib cho liệu pháp điều trị bước đầu ở những người có hoặc không có khả năng ghép tế bào gốc, cũng như để củng cố và điều trị cứu cánh sau khi tái phát ${ }^{3}{ }^{4}$.

Tại bênh viện $K$, hiện nay chưa có nghiên cứu nào đánh giá hiệu quả phác đồ có bortezomib trong điều trị bước đầu đa u tủy xương. Vì vậy chúng tôi tiến hành đề tài này nhằm đánh giá hiêu quả của phác đồ có bortezomib trong điều trị bước đầu đa u tủy xương.

\section{II. ĐỐI TƯợNG VÀ PHƯƠNG PHÁP NGHIÊN CỨU \\ * Đối tượng nghiên cứu \\ a, Tiêu chuẩn lứa chon}

- Bệnh nhân từ 18 tuổi trở lên được chẩn đoán xác định là đa u tủy xương có triệu chứng chưa đước điều trị trước đó.

- Bênh có tổn thương có thể đo lường được.

- Bệnh nhân đồng ý tham gia nghiên cứu.

\section{b, Tiêu chuấn loai trư}

- Bênh thần kinh ngoai biên độ 2 trở lên

- Số lượng bạch câu trung tính tuyệt đối (ANC) $<1000 / \mu \mathrm{L} ;$

- Tiểu câu <70 000/ $\mu \mathrm{L}$;

- AST/ALT > 2lần giới han trên của mức bình thường (ULN) hoặc bilirubin toàn phần > 3 lân ULN.

- Bênh nhân bị nhồi máu cơ tim trong vòng 6 tháng trước đó, suy tim độ III hoăc IV của Hiệp hội Tim mạch New York, đau thắt ngực không kiểm soát được hoặc rối loạn nhịp tim nặng cũng được loại trừ.

*Phương pháp nghiên cứu: Nghiên cứu mô tả tiến cứu được tiến hành trên 44 bệnh nhân đa u tủy xương điều trị bằng phác đồ có bortezomib từ tháng 05 năm 2019 đến tháng 10 năm 2021 tại Khoa Nội Hệ tạo Huyết - Bệnh viện K3 cơ sở Tân Triều.

\section{Các thông số nghiên cứu}

- Đặc điểm lâm sàng của bệnh nhân trước điều trị: tuổi, giới, PS, triệu chứng lâm sàng; đánh giá đáp ứng cơ năng triệu chứng đau theo thang điểm VAS theo đợt điều trị; Đánh giá nguy cơ gãy xương theo Mirel (phụ lục).

- Đặc điểm cận lâm sàng: CT scan toàn thân và MRI cột sống (tính chất khối $u$ hoặc tổn thương xương: số lượng, vị trí, kích thước), đă̆c điểm giải phẩu bệnh, xét nghiệm điện di miển dịch, sinh thiết tủy xương - huyết tủy đồ.
- Đáp ứng điều trị giữa đợt, cuối đợt.

- Đánh giá tác dụng phụ của phác đồ.

\section{* Quy trình nghiên cứu}

- Bước 1: Lựa chọn bệnh nhân tham gia nghiên cứu.

- Bước 2: Tiến hành điều trị bệnh nhân theo phác đồ có Bortezomib.

- Bước 3: Thu thập và xử lý số liệu.

- Bước 4: Hoàn thiện đề tài.

*Phân tích và xử lý số liệu. Các thông tin được mã hoá và xử lý bằng phần mềm SPSS 16.0

*Khía cạnh đạo đức của nghiên cứu. Đây là nghiên cứu có tính chất can thiệp điều trị̆, thuốc bortezomib đã được đưa vào hướng dẫn điều trị Đa u tủy xương của Bộ Y Tế Việt Nam. Nghiên cứu này chỉ nhằm mục đích nâng cao chất lượng điều trị, không nhằm mục đích nào khác.

\section{KẾT QUẢ NGHIÊN CứU}

Bảng 1. Đăc điểm chung bệnh nhân

\begin{tabular}{|c|c|c|}
\hline \multicolumn{2}{|c|}{$\begin{array}{l}\text { Đặc điếm chung của bệnh } \\
\text { nhân }(n=44)\end{array}$} & Giá trị \\
\hline \multicolumn{2}{|r|}{ Tuổi } & $\begin{array}{c}59,05 \pm 11,07 \\
(20-75)\end{array}$ \\
\hline \multirow{2}{*}{ Giới } & Nam & $23(52,3 \%)$ \\
\hline & Nữ & $21(47,7 \%)$ \\
\hline \multicolumn{2}{|r|}{ Chiều cao (m) } & $\begin{array}{l}1,59 \pm 0,07 \\
(1,50-1,72)\end{array}$ \\
\hline \multicolumn{2}{|r|}{ Cân nặng } & $\begin{array}{c}55,48 \pm 7,68 \\
(37-73)\end{array}$ \\
\hline \multirow[t]{5}{*}{ BMI } & & $\begin{array}{c}21,88 \pm 2,87 \\
(16,14-27,48)\end{array}$ \\
\hline & Gầy $<18,5$ & $6(13,6)$ \\
\hline & Bình thương $18,5-22,9$ & $20(45,5)$ \\
\hline & Thứa cân 23-24,9 & $13(29,5)$ \\
\hline & Béo phì $\geq 25$ & $5(11,4)$ \\
\hline \multicolumn{2}{|r|}{ Diện tích da } & $\begin{array}{l}1,56 \pm 0,12 \\
(1,26-1,82)\end{array}$ \\
\hline \multirow{5}{*}{ PS } & 0 & $9(20,5 \%)$ \\
\hline & 1 & $22(50,0 \%)$ \\
\hline & 2 & $9(20,5 \%)$ \\
\hline & 3 & $3(6,8 \%)$ \\
\hline & 4 & $1(2,3 \%)$ \\
\hline & $\mathrm{HCB}$ & $5(11,4 \%)$ \\
\hline
\end{tabular}

Lý do vào viện

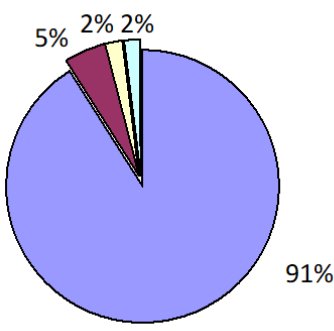

$\square$ Đau xương $\square$ Nổi u xương $\square$ Nổi hạch $\square$ Đau ngực

Biểu đồ 1. Lý do vào viện 
Bảng 2. Đăc điểm tổn thương xương và hạch

\begin{tabular}{|c|c|c|}
\hline \multirow{2}{*}{\multicolumn{2}{|c|}{ Đặc điểm }} & \\
\hline & & n (\%) \\
\hline \multirow{3}{*}{$\begin{array}{l}\text { Số lượng } \\
\text { tổn thương }\end{array}$} & 1 & $2(4,5 \%)$ \\
\hline & 2 & $3(6,8 \%)$ \\
\hline & Nhiều u & $39(88,6 \%)$ \\
\hline \multicolumn{2}{|c|}{$\begin{array}{l}\text { Kích thước tốn thương lớn } \\
\text { nhất trung bình }(\mathrm{mm})\end{array}$} & $\begin{array}{l}37,48 \pm 22,70 \\
(10-95)\end{array}$ \\
\hline \multicolumn{3}{|c|}{ Vị trí tốn thương xương } \\
\hline \multicolumn{2}{|c|}{ Xương sọ } & $14(31,8)$ \\
\hline \multicolumn{2}{|c|}{ Xương hàm } & $6(13,6)$ \\
\hline \multicolumn{2}{|c|}{ Xương cột sống cố } & $10(22,7)$ \\
\hline \multirow{2}{*}{\multicolumn{2}{|c|}{$\begin{array}{l}\text { Xương cột sống ngực } \\
\text { Xương côt sống lưng }\end{array}$}} & $32(72,7)$ \\
\hline & & $33(75,0)$ \\
\hline \multicolumn{2}{|c|}{ Xương đòn } & $6(13,6)$ \\
\hline \multicolumn{2}{|c|}{ Xương ức } & $8(18,2)$ \\
\hline \multicolumn{2}{|c|}{ Xương sườn } & $24(54,5)$ \\
\hline \multicolumn{2}{|c|}{ Xương bả vai } & $5(11,4)$ \\
\hline \multicolumn{2}{|c|}{ Xương chậu } & $21(47,7)$ \\
\hline \multicolumn{2}{|c|}{ Xương cùng } & $9(20,5)$ \\
\hline \multicolumn{2}{|c|}{ Xương chi trên } & $4(9,1)$ \\
\hline Xương & i dưới & $7(15,9)$ \\
\hline \multicolumn{3}{|c|}{ Vị trí khác } \\
\hline \multicolumn{2}{|c|}{ Hach } & $2(4,5)$ \\
\hline \multicolumn{2}{|c|}{ U trung thất } & $2(4,5)$ \\
\hline \multicolumn{2}{|c|}{ Phối } & $1(2,3)$ \\
\hline \multicolumn{2}{|c|}{ Màng phối } & $1(2,3)$ \\
\hline
\end{tabular}

\begin{tabular}{|c|c|c|}
\hline \multicolumn{2}{|c|}{ Phần mềm xoang hàm } & $1(2,3)$ \\
\hline \multicolumn{3}{|c|}{ Tỉ lệ gãy xương bệnh lý: $4(9,1)$} \\
\hline \multicolumn{3}{|c|}{ Bảng 3. Chân đoán thể bệnh đa u tủy xương } \\
\hline \multicolumn{2}{|c|}{ Thế bênh đa u tủy xương } & n(\%) \\
\hline \multirow[t]{2}{*}{$\operatorname{Ig} A$} & Kappa & $4(9,1)$ \\
\hline & Lambda & $3(6,8)$ \\
\hline \multirow[t]{2}{*}{ IgG } & Kappa & $17(38,6)$ \\
\hline & Lambda & $8(18,2)$ \\
\hline \multirow[t]{2}{*}{ IgM } & Kappa & 0 \\
\hline & Lambda & $1(2,3)$ \\
\hline \multirow[t]{2}{*}{$\mathrm{IgE}$} & Kappa & $3(6,8)$ \\
\hline & Lambda & $3(6,8)$ \\
\hline \multirow[t]{2}{*}{ Chuôi nhẹ } & Kappa & 0 \\
\hline & Lambda & $3(6,8)$ \\
\hline \multicolumn{2}{|c|}{ Thể không tiết } & $2(4,5)$ \\
\hline
\end{tabular}

Giai đoạn bệnh ISS

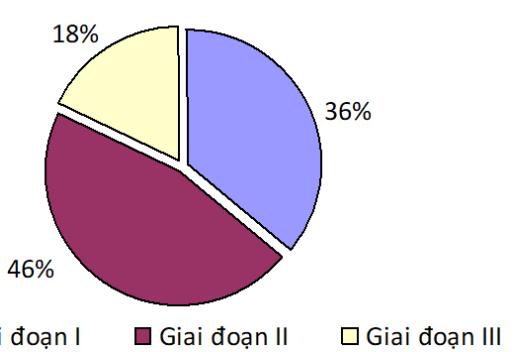

G Giai đoạn I G Giai đoạn II $\quad$ Giai đoạn III
Biêu đồ 2. Giai đoạn bệnh theo ISS

Bảng 4. Tỉ lệ đáp ứng

\begin{tabular}{|c|c|c|c|c|}
\hline Đáp ứng & VTD (n=29) & VCD (n=5) & VRD (n=10) & Chung (n=44) \\
\hline Một phân & $27(93,2)$ & $3(60,0)$ & $9(90,0)$ & $39(88,7)$ \\
\hline Ōn định & $1(3,4)$ & $0(0)$ & $1(10,0)$ & $2(4,5)$ \\
\hline Tiến triến & $1(3,4)$ & $2(40,0)$ & 0 & $3(6,8)$ \\
\hline Tỉ lệ kiếm soát bệnh & $28(96,6)$ & $3(60,0)$ & $10(100)$ & $41(93,2)$ \\
\hline p & \multicolumn{4}{|c|}{0,03} \\
\hline
\end{tabular}

Bảng 5. Tác dụng phu

\begin{tabular}{|c|c|c|c|c|}
\hline Độc tính & VTD (n=29) & VCD (n=5) & VRD (n=10) & Chung (n=44) \\
\hline Hạ bạch cầu & $2(6,9)$ & $1(20)$ & $4(40)$ & $7(15,9)$ \\
\hline Hạ tiếu câu & $3(10,3)$ & 0 & $1(10)$ & $4(9,1)$ \\
\hline Độc tính thần kinh ngoại vi & $8(27,6)$ & 0 & $1(10)$ & $9(20,5)$ \\
\hline Độc tính da & 0 & 0 & $3(30)$ & $3(6,8)$ \\
\hline Viêm phối & $2(6,9)$ & 0 & 0 & $2(4,5)$ \\
\hline
\end{tabular}

\section{BÀN LUẬN}

\subsection{Chẩn đoán}

Tuổi và giới. Độ tuổi trung bình của đa u tủy xương thường gặp 65-74 tuổi, chỉ có $10 \%$ ở độ tuổi dưới 50 và $2 \%$ ở độ tuổi dưới 40 . Tỉ lệ gặp đa u tủy xương ở nam cao hơn nữ với tî lệ nam/nữ 1,41.

Trong nghiên cứu của chúng tôi thu được độ tuổi trung bình của bệnh nhân là 59,05 $\pm 11,07$, thấp nhất là 20 tuổi, cao nhất là 75 tuổi. Tỉ lế giới tính nam/nữ trong nghiên cứu của chúng tôi là 1,1 . Kết quả nghiên cứu của chúng tôi có đô tuổi tương đương nhưng tỉ lệ giới tính nam thấp hơn tác giả Philippe Moreau (2016) với độ tuổi trung bình 59, tỉ lệ nam/nữ 1,565.

Thông số nhân trắc. Chiêu cao trung bình của các bệnh nhân là $1,59 \pm 0,07 \mathrm{~m}$, cân nặng trung bình là $55,48 \pm 7,68$, BMI trung bình là $21,88 \pm 2,87$. Đa số các bênh nhân có BMI trong mức bình thường $45,5 \%$, thừa cân chiếm $29,5 \%$, có $13,6 \%$ bệnh nhân gầy và $11,4 \%$ bệnh nhân béo phì. Diện tích da trung bình của bệnh nhân là $1,56 \pm 0,12$. Các thông số nhân trắc về chiều cao và cân nặng trung bình trong nghiên cứu của chúng tôi tương đương với các chỉ số bình thường của người Việt Nam. 
Lâm sàng. Nghiên cứu của chúng tôi thây bệnh nhân vào viện đa số vì đau xương chiếm $91 \%$, các lý do khác bao gồm: nổi u xương $5 \%$, nổi hạch $2 \%$, đau ngực $2 \%$.

Bểnh nhân đa số có $\mathrm{PS}=1$ chiếm $50 \%$, có $20,5 \%$ bệnh nhân có $P S=0$, có 20,5\% bệnh nhân có $\mathrm{PS}=2,6,8 \%$ bệnh nhân có $\mathrm{PS}=3$ và 1 bệnh nhân $\mathrm{PS}=4$. Chỉ số toàn trạng của bênh nhân ở mức 2->4 đa phần là do biến chứng tại hệ xương dẫn tới đau đớn và hạn chế vận động. Bệnh nhân vào viện có $11,4 \%$ có hội chứng $B$.

Chẩn đoán hình ảnh. Đa số các bệnh nhân có nhiều tổn thương chiếm $88,6 \%$, có $6,8 \%$ bệnh nhân 2 tổn thương và có $4,5 \%$ bệnh nhân có 1 tổn thương. Kích thước tổn thương trung bình là $37,48 \pm 22,70 \mathrm{~mm}$, nhỏ nhất là $10 \mathrm{~mm}$, lớn nhất là $95 \mathrm{~mm}$. Các tổn thương xương thường gặp nhất ở xương cột sống thắt lưng $75 \%$, xương cột sống ngực 72,7\%, xương sườn $54,5 \%$. Tỉ lệ tổn thương xương ở các vị trí khác lần lượt là: xương chậu 47,7\%, xương sọ 31,8\%, xương cột sống cổ $22,7 \%$, xương cùng $20,5 \%$, xương ức 18,2\%, xương chi dưới $15,9 \%$, xương hàm hoặc xương đòn $13,6 \%$, xương bả vai $11,4 \%$, xương chi trên $9,1 \%$. Các vị trí tổn thương ngoài xương bao gồm: hạch $4,5 \%$, u trung thất 4,5\%, phổi 2,3\%, màng phổi 2,3\%, phần mềm xoang hàm $2,3 \%$.

Tỉ lệ gãy xương bệnh lý ghi nhận là 9,1\%. Theo đánh giá nguy cơ gãy xương Mirel, chúng tôi thu được tỉ lệ nguy cơ gãy xương cao là $29 \%$, trung bình $14 \%$, thấp $57 \%$.

Thể bệnh. Theo phân tích của Kyle RA năm 2003 tỉ lệ thể bệnh đa u tủy xương như sau: IgG $52 \%$, IgA 21\%, chuỗi nhẹ Kappa/Lambda 16\%, IgD $2 \%$, tăng 2 dòng $2 \%$, IgM 0,5\%, thể không tiết $6,5 \%{ }^{6}$. Nghiên cứu của chúng tôi thu được thể bệnh đa u tủy xương hay gặp nhất là IgG Kappa $38,6 \%$, IgG Lambda 18,2\%, tiếp theo là IgA kappa chiếm 9,1\%, IgE kappa hoăc IgE lambda hoặc IgA lambda chiếm $6,8 \%$, thể bênh chuỗi nhe lambda chiếm $6,8 \%$, IgM lambda 2,3\%, thể không tiết 4,5\%. Chúng tôi không gặp trường hợp nào của thể bệnh IgM kappa và chuỗi nhe Kappa.

Giai đoạn bệnh. Theo phân loại ISS, nghiên cứu của chúng tôi thu được tỉ lệ giai đoạn I $36 \%$, giai đoạn II $46 \%$, giai đoạn III $18 \%$. Kết quả của chúng tôi tương đương với tác giả Philippe Moreau $2016^{5}$.

\section{2. Điêuu trì}

Hiệu quả phác đồ. Trong nghiên cứu của chúng tôi có $65,9 \%$ bệnh nhân được điều trị bằng phác đồ VTD, $11,4 \%$ VCD và $22,7 \%$ VRD.
Việc lựa chọn phác đồ cho bệnh nhân dựa vào toàn trạng ban đầu, mức lọc cầu thận (bệnh nhân suy thận không sử dụng được thuốc điêu biến miển dịch lenalidomide và thalidomide) và kinh tế của bệnh nhân. Khi phân tích tỉ lệ đáp ứng sau điêu trị chúng tôi thu được, tỉ lệ kiểm soát bệnh của phác đồ VTD là $96,6 \%$, phác đồ VRD là $100 \%$ cao hơn so với phác đồ VCD $60 \%$ với $p=0,03$. Nghiên cứu của chúng tôi cho kết quả tương tự các tác giả: Ann 20134, Kumar 20127, Philippe Moreau $2016^{5}$, Katarina Uttervall $2019^{8}$.

Tác dụng phụ. Độc tính hay gặp nhất sau điều trị là độc tính thần kinh ngoại vi chiếm 9/44 $(20,5 \%)$ gặp chủ yếu ở nhóm điều trị VTD 8/29 $(27,6 \%)$. Độc tính huyết học là hạ bạch cầu và hạ tiểu cầu gặp với tî lệ lần lượt là $13,6 \%$ và 9,1\%; trong đó độc tính hạ bạch cầu xảy ra chủ yếu ở nhóm điều trị phác đồ VRD với tỉ lệ $40 \%$. Độc tính da chỉ gặp 30\% ở nhóm sử dụng VRD do tác dụng phụ thường gặp của lenalidomide, một số bệnh nhẩn trong nghiên cứu khi gặp độc tính da đã phải chuyển đổi về sử dụng phác đồ VTD. Độc tính viêm phổi trong nghiên cứu của chúng tôi chỉ gặp ở nhóm VTD chiếm 2/29 $(6,9 \%)$. Nghiên cứu của chúng tôi cho kết quả tương tự các tác giả Ann 20134; Philippe Moreau $2016^{5}$ và tỉ lệ biến chứng thấp hơn tác giả Brian $2016^{3}$.

Như vậy phác đồ 3 thuốc phối hợp có thuốc điều biến miên dịch VTD hoặc VRD cho hiệu quả điều trị cao hơn so với nhóm bệnh nhân điều trị VCD. Việc lựa chọn điều trị ưu tiên hiện nay là sử dụng phác đồ VTD do thuốc thalidomide đã được chi trả bảo hiểm y tế và phác đồ ít gặp độc tố trên hệ tạo huyết. Tuy nhiên về mặt đáp ứng lâm sàng thì phác đồ VRD có hiệu quả tốt hơn tuy nhiên sự khác biệt so với nhóm VTD không có ý nghĩa thống kê với p>0,05.

\section{KẾT LUẬN}

Điều trị đa u tủy xương bằng phác đồ có bortezomib cho tỉ lệ kiểm soát bệnh cao và ít độc tính. Việc lựa chọn phác đồ ban đầu tùy thuộc vào thể trạng bệnh nhân, các chỉ số xét nghiệm và điều kiện kinh tế. Phác đồ VTD nên được ưu tiên lựa chọn do khả năng kiểm soát bệnh tốt và các thuốc đều được chi trả bảo hiểm y tế.

\section{TÀI LIẸU THAM KHẢO}

1. Jacob $\mathbf{P}$ Laubach. Multiple myeloma: Clinical features, laboratory manifestations, and diagnosis. Uptodate. 2021:1-21.

2. S Vincent Rajkumar. Multiple myeloma: Overview of management. Uptodate. 2020:1-23.

3. Durie BG HA, Abidi MH, et al.,. Bortezomib with lenalidomide and dexamethasone versus lenalidomide and dexamethasone alone in patients 
with newly diagnosed myeloma without intent for immediate autologous stem-cell transplant (SWOG S0777): a randomised, open-label, phase 3 trial. Lancet. 2017;389:519.

4. Ann E Engebretson. Comparable Outcomes With Bortezomib-Cyclophosphamide-Dexamethasone (VCD) and Bortezomib-LenalidomideDexamethasone (VRD) For Initial Treatment Of Newly Diagnosed Multiple Myeloma (MM). Blood. 2013;122(21):3178-3184.

5. Philippe Moreau, Cyrille Hulin, Margaret Macro et al. VTD is superior to VCD prior to intensive therapy in multiple myeloma: results of the prospective IFM2013-04 trial. Blood. 2016:2569-2574
6. Kyle RA, Gertz MA, Witzig TE et al. Review of 1027 patients with newly diagnosed multiple myeloma. Mayo Clin Proc. 2003:21.

7. Shaji Kumar. Randomized, multicenter, phase 2 study (EVOLUTION) of combinations of bortezomib, dexamethasone, cyclophosphamide, and lenalidomide in previously untreated multiple myeloma. Blood. 2012;119(19):4375-4382.

8. Katarina Uttervall, Johanna Borg Bruchfeld, Charlotte Gran et al. Upfront bortezomib, lenalidomide, and dexamethasone compared to bortezomib, cyclophosphamide, and dexamethasone in multiple myeloma. Eur J Haematol. 2019:247-254.

\section{THỰC TRANG CAI THỞ MÁY VÀ MộT SỐ YẾU TỐ LIÊN QUAN ĐẾN CAI THỞ MÁY KÉO DÀI TẠI KHOA HỒI SỨC TÍCH CỰC BỆNH VIỆN BẠCH MAI}

\section{TÓM TẮT}

Mục tiêu: Nghiên cứu nhằm phân loai cai thở máy theo tiêu chí mới của hội nghị đồng thuận quốc tế diễn ra năm 2005 và đánh giá một số yếu tố liên quan đến cai thở máy kéo dài tại khoa hồi sức tích cực bệnh viên Bach Mai. Đối tượng và phương pháp nghiên cứu: 176 bệnh nhân điều trị tại khoa HSTC cân phải thở máy xâm nhập đã cai máy thở thành công được phân loại thành các nhóm cai máy đơn giản, cai máy khó và cai máy kéo dài. Một số yếu tố liên quan cai máy kéo dài và tiên lượng sau cai máy được xác định. Kết quả: Số lượng bệnh nhân theo các nhóm cai máy đơn giản, cai máy khó, cai máy kéo dài lần lượt là 106, 42, 28 tương ứng tỷ lệ 60\%, 24\%, 16\%. Ở bệnh nhân cai máy kéo dài tỷ lệ tử vong hoăc năng xin về $11 \%$, tỷ lệ viêm phổi liên quan đên thở máy $68 \%$ so với 2 nhóm còn lai tỷ lệ này là $3 \%$ và $18 \%$. Chỉ số thơ nhanh nông RSBI $\geq 98$ và $\mathrm{PaCO}_{2} \geq 43 \mathrm{mmHg}$ trong nghiệm pháp tư thở đâu tiên có giá trị tiên lượng độc lập cho cai máy kéo dài. Kết luận: Phân loại mới về cai máy cho thây cai máy kéo dài có liên quan với tăng tỷ lệ nặng xin về hoặc tử vong tại viện. Trong quần thể nghiên cứu, nồng độ CO2 trong máu tăng cao cuối nghiệm pháp tự thở dự đoán cai thở máy kéo dài. Các bác sĩ lâm sàng cần có những chiến lược nhằm cải thiện kết quả cai thở máy.

Tư khóa: Tăng $\mathrm{CO}_{2}$ máu, cai máy kéo dài, ICU, cai thở máy.

\section{SUMMARY \\ INCIDENCE OF WEANING FROM MECHANICAL VENTILATION AND SEVERAL}

\footnotetext{
*Đại hoc Y Hà Nôi

Chịu trách nhiệm chính: Trần Quốc Minh

Email: qcm1923@gmail.com

Ngày nhận bài: 25.10.2021

Ngày phản biên khoa họ: 20.12.2021

Ngày duyệt bài: 30.12 .2021
}

\author{
Trần Quốc Minh*, Lê Thị Diễm Tuyết*
}

\section{FACTORS ASSOCIATED WITH PROLONGED WEANING IN INTENSIVE CARE UNIT OF BACH MAI HOSPITAL}

Purpose: The objective of the present study was to determine the incidence of weaning according to the new categories 2005 and to assess some factors associated with prolonged weaning in ICU of Bach Mai hospital. Methods: 176 patients admitted to the intensive care unit (ICU) and requiring mechanical ventilation were successfully weaned and classified into simple, difficult and prolonged weaning. Factors associated with prolonged weaning and outcomes were determined. Results: The cumulative incidences of simple, difficult, and prolonged weaning were $106(60 \%), 42(24 \%)$ and 28 $(16 \%)$, respectively. Hospital mortality was increased in patients with prolonged (11\%) weaning in comparison with those with simple and difficult weaning (3\%). RSBI $\geq 98$ and $\mathrm{PaCO}_{2} \geq 43 \mathrm{mmHg}$ during the spontaneous breathing trial independently predicted prolonged weaning. Conclusions: The new weaning category prolonged weaning is associated with increased mortality in the ICU. For the overall population, hypercapnia at the end of spontaneous breathing predicts prolonged weaning, clinicians should implement measures aimed at improving weaning outcome.

Keywords: Hypercapnia, Prolonged weaning, ICU, weaning from mechanical ventilation.

\section{I. Đă̆T VẤN ĐỀ}

Cai thở máy là quá trình giảm dần sự hỗ trợ của máy thở, chiếm tới 40 - 50\% tổng thời gian thở máy.Thở máy kéo dài tăng nguy cơ bị các nhiễm khuẩn mắc phải trong bệnh viện, tăng thời gian phải nằm tại khoa Hồi sức và làm tăng chi phí chăm sóc y tế cũng như gánh nặng cho gia đình bệnh nhân và xã hội.

Một hội nghị đồng thuận quốc tế diễn ra năm 